\title{
CONSÓRCIO DE FORRAGEIRAS TROPICAIS COM O SORGO GRANÍFERO EM DUAS LOCALIDADES DO ESTADO DE MINAS GERAIS
}

\author{
CARLOS JULIANO BRANT ALBUQUERQUE ${ }^{1}$, RENATO MENDES DE OLIVEIRA², \\ KAREN MARCELLE DE JESUS SILVA ${ }^{1}$, DORISMAR DAVID ALVES², \\ RAMON COSTA ALVARENGA ${ }^{3}$ e GABRIEL LABECA FERREIRA NOGUEIRA BORGES ${ }^{4}$
}

\author{
${ }^{1}$ Epamig, Unidade Regional Triângulo e Alto Paranaíba, Uberlândia, MG, Brasil, carlosjuliano@epamig.br, \\ karen_marcelle@hotmail.com \\ ${ }^{2}$ Unimontes, Janaúba, MG, Brasil.renatoagronomo@hotmail.com, dorismar.alves@unimontes.br \\ ${ }^{3}$ Embrapa Milho e Sorgo, Sete Lagoas, MG, Brasil.ramon.alvarenga@embrapa.br \\ ${ }^{4}$ Unitri, Uberlândia, MG,Brasil,veterinaria@unitri.edu.br
}

Revista Brasileira de Milho e Sorgo, v.12, n.1, p. 1-9, 2013

\begin{abstract}
RESUMO - O trabalho foi desenvolvido com o objetivo de avaliar o consórcio de gramíneas forrageiras com o sorgo granífero em duas localidades do estado de Minas Gerais. Foram instalados dois experimentos nas fazendas experimentais da Epamig localizadas nos municípios de Leme do Prado e Jaíba. O delineamento adotado foi em blocos casualizados, com quatro repetições. O rendimento de grãos, a altura de plantas e a produção de massa de forragem foram influenciados pelo local de cultivo. Maiores produções de massa de forragem seca foram obtidas no consórcio de sorgo com Panicum maximum em ambas as localidades. O sorgo solteiro apresenta maior rendimento de grãos em ambas as localidades. O consórcio do sorgo com a Brachiaria decumbens e do sorgo com o Andropogon gayanus apresentam maiores produtividades de grãos para as localidades de Jaíba e Leme do Prado, respectivamente.
\end{abstract}

Palavras-chave: Sorghum bicolor; rendimento de grãos; produção de massa de forragem; iLPF.

\section{INTERCROPPING OF TROPICAL FORAGE CROPS WITH GRAIN SORGHUM IN TWO LOCALITIES OF MINAS GERAIS STATE}

\begin{abstract}
This work was carried out in order to evaluate the intercropping of forage grasses with grain sorghum in two localities of Minas Gerais State. Two experiments were set in experimental areas of the Empresa de Pesquisa Agropecuária de Minas Gerais (Epamig), in Leme do Prado and in Jaíba. The design was in randomized blocks with four replications. Grain yield, plant height and productivity of dry matter were affected by the cultivation site. Highest productivity of forage dry matter was observed in the sorghum Panicum maximum Jacq. intercropping, in the two localities. Single sorghum presented greater grain yield in both localities. The intercropping of sorghum with Brachiaria decumbens and sorghum with Andropogon gayanus presented greater grain yield in Jaíba and Leme do Prado, respectively.
\end{abstract}

Key words: Sorghum bicolor; grains yield; forage dry matter; iLPF. 
As regiões Norte e Vale do Jequitinhonha do estado de Minas Gerais têm na pecuária, tanto de corte quanto de leite, uma das principais atividades econômicas. Outra característica dessas localidades é a alta dependência de grãos para formulação de concentrados e misturas múltiplas para suplementação animal, pois a produção da maioria dos cereais é limitada pelos baixos índices pluviométricos, temperaturas elevadas e má distribuição das chuvas, o que caracteriza as duas regiões como as de maior grau de aridez do estado.

Em razão dos grandes investimentos para a formação, a recuperação e a reforma de pastagens, têm-se buscado diversas estratégias para diminuir esses investimentos. Assim, a integração lavoura-pecuária tem se tornado opção vantajosa e beneficiado duas atividades de importância econômica, o que proporciona ganhos mútuos ao produtor. Para promover inovações tecnológicas das atividades agrícolas, tal sistema tem sido objeto de estudo em diversas regiões do mundo (Allen et al., 2007; Tracy \& Zhang, 2008; Balbinot Júnior et al., 2009; Carvalho et al., 2010).

O consórcio de cereais com forrageiras compõe os sistemas denominados integração-lavoura-pecuária (iLP). Atualmente, sistemas de produção estão sendo estudados em função das novas tendências da agricultura moderna. Essa tendência tecnológica busca aprimorar benefícios para o solo, para as plantas e para os animais. No sistema de iLP, os usos da infraestrutura e da mão-de-obra nas propriedades rurais podem ser maximizados, com maiores rendimentos de forragens e de grãos por área. Além disso, a produção de grãos pode reduzir a dependência de insumos externos para alimentação animal e diluir os custos da recuperação das pastagens.

O sorgo vem se destacando como alternativa para a produção de grãos e silagem, uma vez que a cultura apresenta características morfológicas e fisiológicas mais adaptadas ao clima semiárido (Albuquerque et al., 2011). A utilização de híbridos de sorgo para a produção de silagem vem sendo bastante estudada, pois este produz de 40 a 60 toneladas de matéria fresca ha-1. Além disso, produz forragem com 8,3 e 13,8\% de PB, respectivamente para a planta inteira e para as folhas (Fernandes et al., 2004). Em função dessas características, o sorgo tem despertado grande interesse no processo de implantação, renovação ou recuperação de pastagens degradadas, objetivando antecipar o início do pastejo após o plantio e melhorar o aproveitamento da adubação residual. Neste caso, o plantio de sorgo é feito associado a uma gramínea, quando se utiliza o sorgo como silagem ou nos primeiros pastejos (Fernandes et al., 2004).

Para Kichel et al. (1999), entre as alternativas para renovação de pastagens, é comum o consórcio de forrageiras com culturas anuais como arroz, milho ou sorgo. Nesse caso, é realizada a semeadura simultânea da cultura anual e da forrageira ou aproveita-se o potencial das sementes da forrageira existentes no solo, tendo a pastagem formada logo após a colheita da cultura.

Vários estudos têm demonstrado a viabilidade técnica do consórcio de forrageiras com cereais para composição dos sistemas de iLP (Silva et al., 2005; Machado \& Ceccon, 2010; Carvalho et al., 2011). Entretanto, a inconsistência dos resultados obtidos em diferentes regiões evidencia a importância de pesquisas regionalizadas. Para tanto, é necessário que se conheçam quais interações e interferências ocorrem na consorciação do sorgo com gramíneas forrageiras e, dessa forma, identificar qual espécie melhor se adapta ao sistema de consórcio.

O objetivo deste trabalho foi avaliar o consórcio de diferentes gramíneas forrageiras tropicais com o sorgo granífero para o Sistema de iLP em duas localidades do estado de Minas Gerais, utilizando a análise das principais características de interesse agronômico. 


\section{Material e Métodos}

O experimento foi conduzido na Fazenda Experimental de Acauã (Feac), situada no médio Jequitinhonha, município de Leme do Prado, MG, e na Fazenda Experimental de Jaíba (Feja), localizada no município de Jaíba, MG, ambas pertencentes à Empresa de Pesquisa Agropecuária de Minas Gerais (Epamig). A Feac está situada a $812 \mathrm{~m}$ de altitude, nas coordenadas $17^{\circ} 03^{\prime}$ latitude Sul e $42^{\circ}$ 48' longitude Oeste, com temperatura média anual de $21,6{ }^{\circ} \mathrm{C}$ e precipitação média anual de $1000 \mathrm{~mm}$ em um Latossolo Vermelho Amarelo. A Feja está situada a uma altitude de $516 \mathrm{~m}$, nas coordenadas $14^{\circ} 47^{\prime}$ de latitude Sul e $43^{\circ} 18^{\prime}$ de longitude Oeste, com temperatura média anual de $28^{\circ} \mathrm{C}$ e precipitação média anual de $750 \mathrm{~mm}$ em um Latossolo Vermelho Eutrófico.

Os experimentos foram implantados em regime sequeiro na primeira quinzena de dezembro de 2008. Os dados médios de temperatura e precipitação pluvial por decêndios, durante a condução do sorgo granífero em cada localidade, são apresentados na Figura 1.

Para a caracterização química do solo, nas duas localidades, foram coletadas 20 amostras simples na camada de 0 a $20 \mathrm{~cm}$ de profundidade, que constituíram uma amostra composta, analisada no Laboratório de Fertilidade da Epamig em Nova Porteirinha, MG. Os resultados das análises de solos para Leme do Prado e Jaíba foram respectivamente: $\mathrm{pH}$ em $\mathrm{H} 2 \mathrm{O}(5,5$ e 6,9$)$; matéria orgânica $\left(3,8\right.$ e 1,9 dag $\left.\mathrm{kg}^{-1}\right)$; fósforo $(58,5$ e

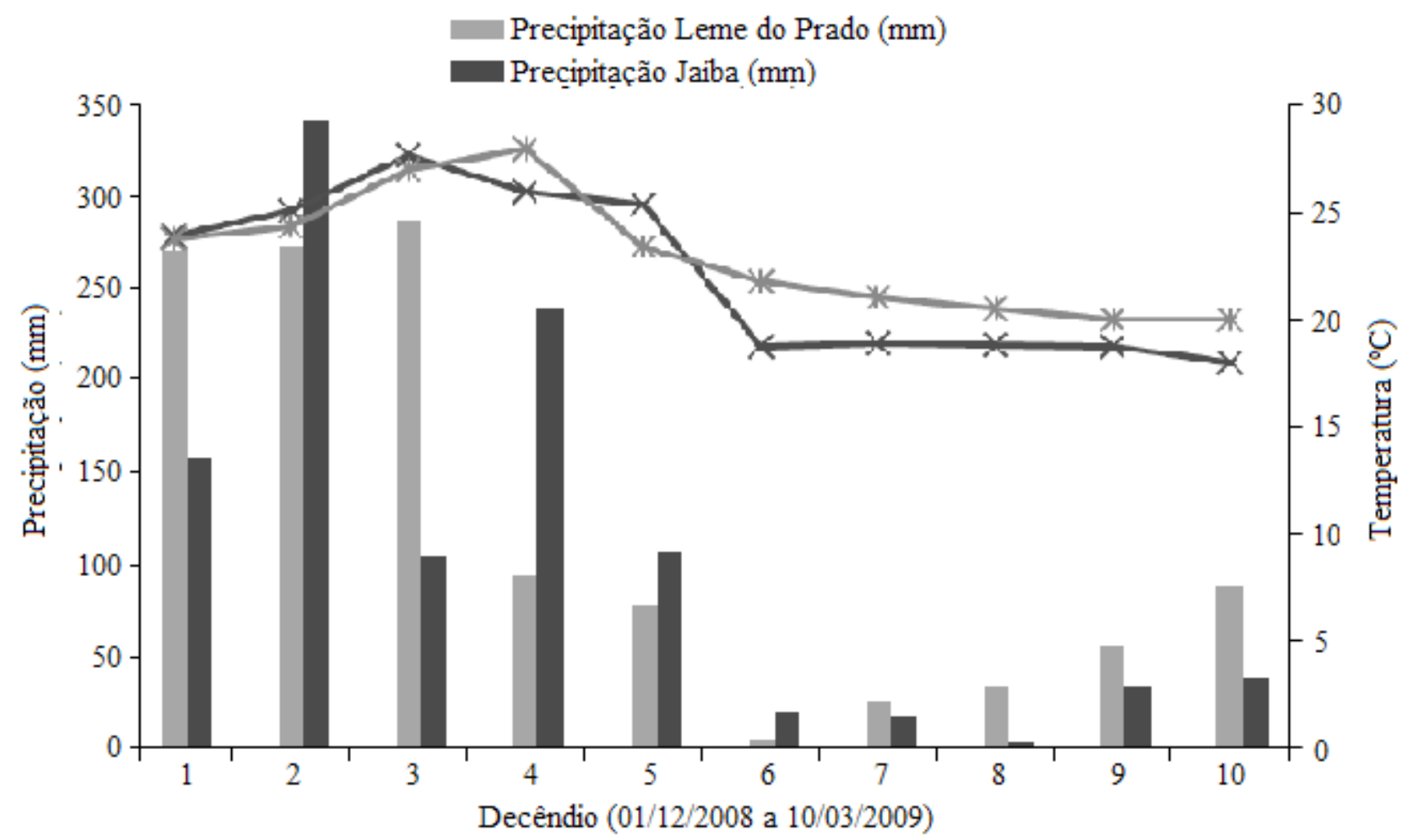

FIGURA 1. Dados médios de temperatura e precipitação pluvial por decêndio, em Jaíba e Leme do Prado, de 01/12/2008 a 10/04/2009. 
8,1 $\left.\mathrm{mg} \mathrm{dm}^{-3}\right)$; potássio $\left(55,0\right.$ e 136,0 $\left.\mathrm{mg} \mathrm{dm}^{-3}\right)$; cálcio (4,0 e 7,2 $\left.\mathrm{cmol}_{\mathrm{c}} \mathrm{dm}^{-3}\right)$; magnésio (1,4 e 1,4 $\mathrm{cmol}_{\mathrm{c}} \mathrm{dm}^{-}$ $\left.{ }^{3}\right)$; alumínio (0,0 e $\left.0,0 \mathrm{cmol}_{\mathrm{c}} \mathrm{dm}^{-3}\right) ; \mathrm{H}+\mathrm{Al}(6,4$ e 1,2 $\left.\mathrm{cmol}_{\mathrm{c}} \mathrm{dm}^{-3}\right) ; \mathrm{SB}\left(5,7\right.$ e $\left.9,1 \mathrm{cmol}_{\mathrm{c}} \mathrm{dm}^{-3}\right) ; \mathrm{T}(12,1$ e 10,9 $\left.\mathrm{cmol}_{\mathrm{c}} \mathrm{dm}^{-3}\right) ; \mathrm{V}(47,0$ e $88,0 \%) ; \mathrm{m}(0,0$ e $0,0 \%)$; boro $\left(0,4\right.$ e $\left.1,1 \mathrm{mg} \mathrm{dm}^{-3}\right)$; cobre $\left(0,3\right.$ e $\left.0,9 \mathrm{mg} \mathrm{dm}^{-3}\right)$; ferro (33,2 e 6,7 $\left.\mathrm{mg} \mathrm{dm}^{-3}\right)$; manganês $\left(8,5\right.$ e $\left.85,9 \mathrm{mg} \mathrm{dm}^{-3}\right)$; zinco $\left(2,1\right.$ e $\left.20,7 \mathrm{mg} \mathrm{dm}^{-3}\right)$.

$\mathrm{O}$ delineamento experimental foi em blocos casualizados, com quatro repetições. Os tratamentos utilizados foram sete espécies de gramíneas forrageiras consorciadas com o sorgo granífero, além da testemunha (sorgo em cultivo exclusivo). Os tratamentos foram definidos da seguinte forma: a) Brachiaria decumbens; b) B. brizantha; c) B. ruziziensis; d) Cenchrus ciliaris cv. Áridus; e) C. ciliaris cv. 131; f) Panicum maximum cv. Marandu; g) Andropogon gayanus; e h) sorgo solteiro (testemunha). A escolha das forrageiras foi baseada no amplo uso e na adaptação destas espécies em diversas propriedades rurais nas localidades em estudo.

No experimento conduzido em Leme do Prado, utilizou-se 3,0 $\mathrm{t} \mathrm{ha}^{-1}$ de calcário dolomítico (PRNT de 80\%) para correção da acidez do solo.

A semeadura foi realizada de forma manual, distribuindo uniformemente 10 sementes por metro. Aproximadamente 15 dias após a semeadura do sorgo, foi realizado um desbaste, deixando um estande e 140 mil plantas ha-1. A semeadura das forrageiras consorciadas foi realizada no plantio junto com o adubo na mesma data do sorgo, sendo adotada a quantidade de 420 pontos de valor cultural por hectare. As parcelas foram constituídas de seis linhas de $5 \mathrm{~m}$, espaçadas $60 \mathrm{~cm}$. A área útil para cultura do sorgo foi constituída das duas linhas centrais, desconsiderando-se $0,5 \mathrm{~m}$ de bordadura de cada lado da parcela.
Com base nos resultados da análise de solo, foi realizada a adubação de plantio com $350 \mathrm{~kg} \mathrm{ha}^{-1}$ formulado 4: 30: 10 (NPK). Em cobertura, utilizou-se $200 \mathrm{~kg} \mathrm{ha}^{-1}$ de ureia e $120 \mathrm{~kg} \mathrm{ha}^{-1}$ de cloreto de potássio. Para o controle de plantas daninhas, foi utilizado, na pós-emergência, herbicida a base de atrazina na dosagem de 41 ha $^{-1}$.

Foram realizadas pulverizações, por meio de um pulverizador costal, com o inseticida deltametrina, na dosagem de $200 \mathrm{ml} \mathrm{ha}^{-1}$, para controle da lagarta-do-cartucho [Spodoptera frugiperda (J. E. Smith) (Lepidoptera: Noctuidae)] quando 20\% das plantas apresentavam-se com sintomas da presença dessa praga.

Foram avaliadas a altura de plantas e a produtividade de grãos para a cultura do sorgo e a produção de massa de forragem seca para as gramíneas forrageiras.

A altura de planta foi mensurada em 20 plantas da área útil da parcela, da inserção da panícula superior até o solo, com auxílio de uma régua graduada, após o florescimento.

A colheita foi realizada de forma manual, sendo colhida somente a panícula quando se encontrava no ponto de maturidade fisiológica. Foi pesada a produção da parcela e posteriormente extrapolada para um hectare.

As avaliações relativas ao desenvolvimento das espécies de forrageiras foram efetuadas com uma unidade amostral metálica de forma retangular e tamanho de $1,0 \times 0,4 \mathrm{~m}\left(0,4 \mathrm{~m}^{2}\right)$. Essa unidade foi lançada aleatoriamente em três pontos no centro das parcelas, onde foram coletadas as informações referentes às forrageiras, que foram colhidas no inverno após formação do banco de sementes no solo com o corte ao nível do solo. As forrageiras foram pesadas e posteriormente secas em estufa de aeração forçada, a $65^{\circ} \mathrm{C}$, por $72 \mathrm{~h}$, para a determinação do teor de matéria seca. 
Os dados obtidos foram inicialmente submetidos a uma análise de variância individual por local para verificar a aditividade dos dados, a normalidade dos erros e a homogeneidade das variâncias. Posteriormente, realizou-se análise conjunta, considerando-se os dois locais.

\section{Resultados e Discussão}

Para a altura de plantas, não foi observado efeito significativo dos consórcios utilizados e nem na interação consórcio x local. Já entre os locais, foi observado efeito altamente significativo $(\mathrm{p} \leq 0,01)$. O coeficiente de variação $(\mathrm{CV})$ foi considerado baixo, com valor de 4,36\% para altura de plantas (Tabela 1 ).

No experimento conduzido em Leme do Prado, não foi observada diferença para as alturas de plantas do sorgo granífero. Nesta localidade, o sorgo apresentou altura média de 1,24 $\mathrm{m}$ em todos os consórcios. A mesma tendência foi constatada em Jaíba, considerando o efeito dos consórcios; nesse caso, as plantas apresentaram-se com 1,36 m (Tabela 1). Esses resultados coincidem com os relatos de Kluthcouski \& Aidar (2003) e Mateus et al. (2011), nos quais os consórcios com forrageiras não afetaram o desenvolvimento das plantas de sorgo, pois a mesma tem uma grande capacidade de competição, tendo condições de obter desempenho semelhante aos cultivos solteiros.

A interação local versus consórcio evidenciou efeito significativo na altura das plantas para a maioria dos tratamentos. Apenas o consórcio do sorgo com $A$. gayanus e o sorgo solteiro apresentaram alturas das plantas estatisticamente similares.

Para o rendimento de grãos do sorgo, foi observado efeito $(\mathrm{p} \leq 0,01)$ dos consórcios e locais avaliados, além da interação consórcio x local ( $\mathrm{p} \leq$ 0,01). O CV foi considerado baixo, com valor de $6,76 \%$ (Tabela 2).

Em todos os consórcios, foi observada redução na produtividade de grãos. Ao analisar em termos percentuais as médias gerais das duas localidades,

TABELA 1. Altura de plantas do sorgo (m) em função dos diferentes consórcios e localidades. ${ }^{1}$

\begin{tabular}{lccc}
\hline \multirow{2}{*}{ Consórcios } & \multicolumn{2}{c}{ Localidades } & \multirow{2}{*}{ Médias } \\
\cline { 2 - 3 } & Leme do Prado & Jaíba & 1,28 \\
Sorgo + Andropogon gayanus & $1,25 \mathrm{Aa}$ & $1,32 \mathrm{Aa}$ & 1,30 \\
Sorgo + Cenchrus ciliares cv. Áridus & $1,25 \mathrm{Ab}$ & $1,35 \mathrm{Aa}$ & 1,29 \\
Sorgo + Brachiaria brizantha & $1,23 \mathrm{Ab}$ & $1,36 \mathrm{Aa}$ & 1,30 \\
Sorgo + Cenchurus ciliares cv. 131 & $1,20 \mathrm{Ab}$ & $1,40 \mathrm{Aa}$ & 1,30 \\
Sorgo + Panicum maximum Jacq. & $1,23 \mathrm{Ab}$ & $1,38 \mathrm{Aa}$ & 1,29 \\
Sorgo + Brachiaria decumbens & $1,23 \mathrm{Ab}$ & $1,36 \mathrm{Aa}$ & 1,33 \\
Sorgo + Brachiaria ruziziensis & $1,26 \mathrm{Ab}$ & $1,40 \mathrm{Aa}$ & 1,34 \\
Sorgo solteiro & $1,31 \mathrm{Aa}$ & $1,38 \mathrm{Aa}$ & \\
\hline Médias & 1,24 & 1,36 & \\
\hline CV $(\%)$ & \multicolumn{2}{c}{4,36} & \\
\hline
\end{tabular}

${ }^{1}$ Médias seguidas de mesma letra, maiúscula na coluna e minúscula na linha, não diferem entre si $(\mathrm{p}<0,05)$, pelo teste de Scott-Knott. 
é possível visualizar uma redução na produção de grãos de até $46,08 \%$ para o consórcio $P$. maximum com sorgo, ou seja, 3,0 t ha $\mathrm{ha}^{-1}$ a menos que o sorgo solteiro (Tabela 2).

No experimento conduzido em Leme do Prado, o sorgo solteiro apresentou maior rendimento de grãos, seguido do tratamento sorgo + A. gayanus (redução na produtividade de 9,22\%) e dos tratamentos sorgo $+B$. brizantha (redução na produtividade de 29,73\%), sorgo com $C$. ciliaris $\mathrm{cv}$. 131 (redução na produtividade de 31,96\%), sorgo + B. ruziziensis (redução na produtividade de 33,86\%) e sorgo $+P$. maximum (redução na produtividade de 39,11\%). Ainda nessa localidade, os consórcios sorgo com C. ciliaris cv. Áridus e sorgo com B. decumbens apresentaram menores produtividades (Tabela 2).

No experimento conduzido em Jaíba, o sorgo solteiro também apresentou o maior rendimento de grãos e os demais tratamentos afetaram o rendimento dos grãos (Tabela 2). Entre os consórcios, os melhores resultados no rendimento de grãos ocorreram para o sorgo com $B$. decumbens (redução na produtividade de $8,46 \%$ ), sorgo com $A$. gayanus (redução na produtividade de $20,92 \%$ ), seguido pelo sorgo com C. ciliaris cv. Áridus (redução na produtividade de $16,47 \%$ ) e sorgo com $B$. brizantha (redução na produtividade de 19,58\%). Já os consórcios de sorgo com C. ciliaris cv. 131, sorgo com B. ruziziensis e sorgo com $P$. maximum apresentaram as piores produtividades, respectivamente, nesta localidade; neste caso, observaram-se reduções na produtividade de 30,42 até 39,32\% (Tabela 2).

As espécies do gênero das braquiárias têm sido bastante utilizadas no sistema de iLP (Pariz et al., 2011). Esses autores afirmam que os consórcios de forrageiras com milho também provocam redução na produtividade de grãos. Evidenciam ainda que a taxa de germinação e o uso de sementes peletizadas das diferentes forrageiras podem afetar o rendimento final de grãos.

Ao avaliar o potencial do sorgo granífero, forrageiro e corte pastejo para o consórcio com

TABELA 2. Rendimento de grãos $\left(\mathrm{t} \mathrm{ha}^{-1}\right)$ em função dos diferentes consórcios e das duas localidades. ${ }^{1}$

\begin{tabular}{lccc}
\hline \multirow{2}{*}{ Consórcios } & \multicolumn{2}{c}{ Localidades } & \multirow{2}{*}{ Médias } \\
\cline { 2 - 3 } & Leme do Prado & Jaíba & 5,52 \\
Sorgo + Andropogon gayanus & $5,71 \mathrm{Ba}$ & $5,33 \mathrm{Ca}$ & 4,40 \\
Sorgo + Cenchrus ciliares cv. Áridus & $3,18 \mathrm{Db}$ & $5,63 \mathrm{Ca}$ & 4,91 \\
Sorgo + Brachiaria brizantha & $4,42 \mathrm{Cb}$ & $5,42 \mathrm{Ca}$ & 4,48 \\
Sorgo + Cenchurus ciliares cv. 131 & $4,28 \mathrm{Ca}$ & $4,69 \mathrm{Da}$ & 3,51 \\
Sorgo + Panicum maximum Jacq. & $3,83 \mathrm{Ca}$ & $3,19 \mathrm{Fb}$ & 4,69 \\
Sorgo + Brachiaria decumbens & $3,22 \mathrm{Db}$ & $6,17 \mathrm{Ba}$ & 4,12 \\
Sorgo + Brachiaria ruziziensis & $4,16 \mathrm{Ca}$ & $4,09 \mathrm{Ea}$ & 6,51 \\
Sorgo solteiro & $6,29 \mathrm{Aa}$ & $6,74 \mathrm{Aa}$ & \\
\hline Médias & 4,69 & 4,85 & \\
\hline CV $(\%)$ & \multicolumn{3}{c}{6,76} \\
\hline
\end{tabular}

${ }^{1}$ Médias seguidas de mesma letra, maiúscula na coluna e minúscula na linha, não diferem entre si $(\mathrm{p}<0,05)$, pelo teste de Scott-Knott. 
B. brizantha no município de Sete Lagoas, MG, Rodrigues et al. (2004) concluíram que o primeiro (sorgo granífero + forragem) mostrou-se menos adequado, uma vez que as culturas concorreram entre si, propiciando redução da produtividade de grãos e da pastagem. Os mesmos autores reportaram produtividades semelhantes aos deste trabalho, com valores entre 4,89 $\mathrm{t} \mathrm{ha}^{-1}$ a $6,14 \mathrm{t} \mathrm{ha}^{-1}$ (Tabela 2).

A interação local versus consórcio mostrou diferenças entre as produtividades de grãos na metade dos consórcios. Os consórcios de sorgo com A. gayanus, sorgo com C. ciliares cv. 131, sorgo com B. ruziziensis e o sorgo solteiro apresentaram produtividades estatisticamente similares nas diferentes localidades.

Para as gramíneas forrageiras, foram observadas diferenças na produção de massa de forragem seca (PMFS) em função das localidades $(p \leq 0,01)$ e dos consórcios ( $\mathrm{p} \leq 0,05)$ (Tabela 3 ).

Nas duas localidades estudadas, o consórcio sorgo com P. maximum propiciou maiores produções de massa de forragem. Em Leme do Prado, foram observadas menores produções de forragem nos consórcios de sorgo com A. gayanus, C. ciliaris cv. Áridus, C. ciliaris cv. 131 e B. ruziziensis. No ensaio de Jaíba, verificaram-se menores produtividades de forragem nos consórcios do sorgo com A. gayanus, C. ciliaris cv. Áridus e B.ruziziensis.

A interação local versus tratamentos mostrou diferenças entre as PMFs na maioria dos consórcios. A exceção foi para os consórcios sorgo com A. gayanus e sorgo com B. ruziziensis, os quais apresentaram produtividades estatisticamente similares.

Alguns fatores podem justificar as maiores produções de forragem na maioria das gramíneas no experimento conduzido em Jaíba. O solo da área experimental de Jaíba é originado de rochas com altos teores de cálcio e potássio, conferindo alta soma de bases (SB) e alta saturação de bases (V\%). Além disso, por se tratar de espécie $\mathrm{C} 4$, as forrageiras tropicais respondem a altas incidências de luz. As maiores

TABELA 3. Produção de massa de forragem seca $\left(\mathrm{t} \mathrm{ha}^{-1}\right)$ de gramíneas forrageiras em função dos diferentes consórcios e das duas localidades. ${ }^{1}$

\begin{tabular}{lccc}
\hline \multirow{2}{*}{ Consórcios } & \multicolumn{2}{c}{ Localidades } & \multirow{2}{*}{ Médias } \\
\cline { 2 - 3 } & Leme do Prado & Jaíba & \\
\hline Sorgo + Andropogon gayanus & $3,08 \mathrm{Da}$ & $2,79 \mathrm{Ea}$ & 3,85 \\
Sorgo + Cenchrus ciliares cv. Áridus & $2,91 \mathrm{Db}$ & $4,78 \mathrm{Ea}$ & 7,07 \\
Sorgo + Brachiaria brizantha & $5,46 \mathrm{Cb}$ & $8,67 \mathrm{Ca}$ & 5,10 \\
Sorgo + Cenchurus ciliares cv. 131 & $2,72 \mathrm{Db}$ & $7,48 \mathrm{Da}$ & 9,02 \\
Sorgo + Panicum maximum Jacq. & $7,84 \mathrm{Ab}$ & $10,19 \mathrm{Aa}$ & 7,85 \\
Sorgo + Brachiaria decumbens & $6,28 \mathrm{Bb}$ & $9,41 \mathrm{Ba}$ & 3,27 \\
Sorgo + Brachiaria ruziziensis & $3,32 \mathrm{Da}$ & $3,21 \mathrm{Ea}$ & 2,94 \\
Sorgo solteiro & $3,08 \mathrm{Da}$ & $2,79 \mathrm{Ea}$ & \\
\hline Médias & 4,51 & 6,64 & \\
\hline CV $(\%)$ & \multicolumn{2}{c}{7,80} & \\
\hline
\end{tabular}

${ }^{1}$ Médias seguidas de mesma letra, maiúscula na coluna e minúscula na linha, não diferem entre si $(\mathrm{p}<0,05)$, pelo teste de Scott-Knott. 
taxas de luminosidade, devido à posição geográfica de Jaíba, podem ter proporcionado incrementos na produção de forragem destas gramíneas. De acordo com Rolim (1980), a maioria das plantas forrageiras tem taxa fotossintética maximizada quanto maior a luminosidade disponível. É importante destacar que Leme do Prado situa-se em região de maior altitude quando comparada a Jaíba e que temperaturas baixas podem afetar o desenvolvimento das forrageiras. Comparada a Jaíba, a área experimental de Leme do Prado apresenta temperatura média cerca de $6{ }^{\circ} \mathrm{C}$ inferior.

Os resultados obtidos indicam que a técnica de consórcio do sorgo com diferentes gramíneas forrageiras permite a reforma da pastagem nas regiões estudadas. Vale a pena ressaltar que o pasto permaneceu verde por período mais extenso, com visível rebrota durante o período seco. Tal fato deve-se ao aproveitamento dos adubos residuais pelas forrageiras e ao melhor desenvolvimento radicular por ação da melhoria da fertilidade do solo com a adoção da técnica.

\section{Conclusões}

O rendimento de grãos, a altura de plantas e a produção de massa de forragem seca são influenciadas pelas condições edafoclimáticas de cultivo e pelo consórcio.

Para a produção de forragem, o melhor consórcio é o sorgo com Panicum maximum em ambas as localidades.

O sorgo em cultivo exclusivo apresenta maior rendimento de grãos quando comparado ao consorciado em ambas as localidades.

O consórcio do sorgo com $B$. decumbens e do sorgo com $A$. gayanus apresentam maior rendimento de grãos para as localidades de Jaíba e Leme do Prado, respectivamente.

\section{Agradecimentos}

À Fundação de Amparo à Pesquisa do Estado de Minas Gerais (Fapemig), pela concessão de bolsas, e ao Banco do Nordeste/Etene Fundeci, pelo apoio financeiro.

\section{Referências}

ALBUQUERQUE, C. J. B.; VON PINHO, G. V.; RODRIGUES, J. A. S.; BRANT, R. S.; MENDES, M. C. Espaçamento e densidade de semeadura para o sorgo granífero no semiárido. Bragantia, Campinas, v. 70, p. 278-285, 2011.

ALLEN, V. G.; BAKER, M. T.; SEGARRA, E.; BROWN, C. P. Integrated irrigated crop livestock systems in dry climates. Agronomy Journal, Madison, v. 99, p. 346-360, 2007.

ALVARENGA, R. C.; PORFIRIO-DA-SILVA, V.; NETO, M. M. G.; VIANA, M. C. M.; VILELA. L. Sistema integração lavoura-pecuária-floresta: condicionamento do solo e intensificação da produção de lavouras. Informe Agropecuário, Belo Horizonte, v. 31, p. 59-67, 2010.

BALBINOT JÚNIOR, A. A.; MORAES, A.; VEIGA, M.; PELISSARI, A.; DIECKOW, J. Integração lavourapecuária: intensificação de uso de áreas agrícolas. Ciência Rural, Santa Maria, v. 39, p. 1925-1933, 2009.

BORGHI, E.; CRUSCIOL, C. A. C. Produtividade de milho, espaçamento e modalidade de consorciação com Brachiaria brizantha no sistema plantio direto.

Pesquisa Agropecuária Brasileira, Brasília, DF, v. 42, p. 163-171, 2007.

CARVALHO, M. A; YAMASHITA, O. M; ROQUE, C. G; NOETZOLD, R. Produtividade de arroz no sistema integração lavoura- pecuária com o uso de doses 
reduzidas de herbicida. Bragantia, Campinas, v. 70, p. 33-39, 2011.

CARVAlHO, P. C. F.; ANGHINONI, I.; MORAES, A.; SUlC, R, M.; LANG, C. R.; FLORES, J. P. C.; LOPES, M. L. T.; SILVA, J. L. S.; CONTE, O.; WESP, C. L.; LEVIEN, R.; FONTANELI, R. S.; BAYER, R. Managing grazing animals to achieve nutrient cycling and soil improvement in no-till integrated systems. Nutrient Cycling in Agroecosystems, Dordrecht, v. 88, p. 259-273, 2010.

FERNANDES, L. O.; MACHADO, H. C.; MENDONÇA, V. J. C.; LANDIN, A. M. S.; PAIVA, D. C. Produção animal em diferentes gramíneas, associadas ou não ao sorgo AG 2501, no processo de renovação de pastagens. FAZU em Revista, Uberaba, p. 36-45, 2004.

KICHEL, A. N.; MIRANDA, C. H.; ZIMMER, A. H. Degradação de pastagens e produção de bovinos de corte com a integração x pecuária. In: SIMPÓSIO DE PRODUÇÃO DE GADO DE CORTE, 1., 1999, Viçosa, MG. Anais... Viçosa, MG: UFV, 1999. p. 201-234.

KONDO, M. K.; BRANT, C. J.; ALBUQUERQUE, B.; WENDLING, P. B. S.; CARDOSO, M. M. J. Efeito de coberturas vegetais sobre os atributos fisicos do solo e características agronômicas do sorgo granifero. Bioscience Journal, Uberlândia, v. 28, p. 33-40, 2012. Suplemento.

MATEUS G. P.; CRUSCIOL, C. A. C.; BORGHI, E.;
PARIZ, C. M.; COSTA, C.; OLIVEIRA, J. P. F. de. Adubação nitrogenada de sorgo granífero consorciado com capim em sistema de plantio direto.

Pesquisa Agropecuária Brasileira, Brasília, DF, v. 46, p. 1161-1169, 2011.

PARIZ, C. M.; ANDREOTTI, M.; AENHA, M. V.; BERGAMASCHINE; MELLO, L. M. M.; LIMA, R. C. Produtividade de grãos de milho e massa seca de braquiárias em consórcio no sistema de integração lavoura-pecuária. Ciência Rural, Santa Maria, v. 1, p. 875-882, 2011.

RIBAS, P. M. Sorgo: introdução e importância econômica. Sete Lagoas: Embrapa Milho e Sorgo, 2003. 16 p. (Embrapa Milho e Sorgo. Documentos, 26).

RODRIGUES, J. A. S.; ALVARENGA, R. C.; KARAM, D.; SANTOS, F. G. Implantação de pastagem de Braquiária brizanta consorciado com diferentes cultivares de Sorgo. In: CONGRESSO NACIONAL DE MILHO E SORGO, 25., 2004, Cuiabá. Sete Lagoas: ABMS/Embrapa Milho e Sorgo/Empaer, 2004. CD-ROM. Seção Trabalhos.

ROLIM, F. A. Estacionalidade de produção de forragens. In: SIMPÓSIO SOBRE MANEJO DE PASTAGEM, 6., 1980, Piracicaba. Anais... Esalq/USP, 1980. p. 533-565.

TRACY, B. F.; ZHANG, Y. Soil compaction, corn yield response, and soil nutrient pool dynamics within an integrated crop-livestock system in Illinois. Crop Science, Madison, v. 48, p. 1211-1218, 2008. 